\title{
Arsenic trioxide enhances the cytotoxic effect of cisplatin in head and neck squamous cell carcinoma cell lines
}

\author{
ULANA KOTOWSKI, GREGOR HEIDUSCHKA, MARKUS BRUNNER, \\ BOBAN M. EROVIC, HELGA MARTINEK and DIETMAR THURNHER \\ Department of Otorhinolaryngology, Head and Neck Surgery, Medical University of Vienna, A-1090 Vienna, Austria
}

Received December 29, 2011; Accepted March 1, 2012

DOI: $10.3892 / \mathrm{ol} .2012 .643$

\begin{abstract}
Arsenic trioxide (ATO) has been approved for the treatment of relapsed acute promyelocytic leukaemia. The aim of this study was to determine whether ATO would lead to cell death in head and neck squamous cell carcinoma (HNSCC) cell lines and whether it was able to enhance the cytotoxicity of cisplatin, a standard chemotherapeutic agent. The four HNSCC cell lines SCC9, SCC25, CAL27 and FADU were treated with ATO or cisplatin alone or with ATO and cisplatin in combination. Cytotoxicity assays, immunohistochemistry, western blot analysis and flow cytometry were carried out. Possible interactions between the two drugs were calculated using the Chou-Talalay equation. Ther results demonstrated a synergistic cytotoxic effect of the combination of ATO and cisplatin at high doses. The two agents induced apoptosis in all four HNSCC cell lines. In conclusion, this study showed that ATO is a promising therapeutic drug with cytotoxic effects in HNSCC. We demonstrated a synergistic effect in the combined treatment with cisplatin at high doses.
\end{abstract}

\section{Introduction}

Head and neck squamous cell carcinoma (HNSCC) is a common malignant disease with more than 600,000 new cases registered worldwide every year (1). Despite improved treatment options, including surgery, radiation and chemotherapy, HNSCC is associated with a high mortality rate. The overall 5-year survival rate of approximately $50 \%$ has not changed over the last decades. As such, new therapeutic agents in the treatment of head and neck cancer are required. One objective in cancer research is to find novel drugs that induce apoptosis in tumor cells. Another approach is to identify new combinations of agents that improve therapeutic results and reduce adverse effects.

Correspondence to: Dr Dietmar Thurnher, Department of Otorhinolaryngology, Head and Neck Surgery, Medical University of Vienna, Waehringer Guertel 18-20, A-1090 Vienna, Austria E-mail: dietmar.thurnher@meduniwien.ac.at

Key words: arsenic trioxide, cisplatin, head and neck cancer, synergism, apoptosis
Arsenic is an odorless and tasteless semimetal and has been used in medical history for more than 2,400 years (2). Arsenic preparations were prescribed for the treatment of various diseases. In 1910, Paul Ehrlich identified arsphenamine, an organic arsenical, also known as salvarsan or compound 606 (3). It was applied for the treatment of syphilis prior to the introduction of penicillin. Currently, melarsoprol, a trivalent organic melaminophenyl arsenical, is used for the treatment of late-stage human African trypanosomiasis infections (4). Arsenic trioxide (ATO, $\mathrm{As}_{2} \mathrm{O}_{3}$ ), a trivalent form of arsenic, has been established for the treatment of acute promyelocytic leukaemia (APL). In this disease, ATO is capable of inducing complete remission even in relapsed patients resistant to conventional chemotherapeutic agents $(5,6)$. Of note, the common side effects of ATO treatment are limited to gastrointestinal disorders, cough, fatigue and skin rash, and myelosuppression is minimal (7).

Besides APL, ATO was found to be an effective treatment option in other hematological malignancies and solid tumors. Promising in vitro effects of ATO on gastric cancer (8), HNSCC (9), neuroblastoma (10), esophageal (11), prostate and ovarian carcinomas (12) have been reported. Furthermore, Phase II studies of ATO in patients with relapsed or refractory multiple myeloma (13), metastatic melanoma (14), hepatocellular carcinoma (15) and myelodysplatic syndromes (16) have been carried out.

As yet, the combined effect of ATO with standard chemotherapeuticals has not been described in HNSCC. Therefore, the aim of this study was to evaluate the potential of ATO in enhancing the effect of cisplatin in the four HNSCC cell lines SCC9, SCC25, CAL27 and FADU as well as to confirm previously published data. For a better understanding of the apoptosis-inducing mechanisms of ATO, we investigated the expression of the anti-apoptotic protein Mcl-1 (myeloid cell leukemia protein) in the four cell lines. Mcl-1 is a member of the Bcl-2 family and is involved in inhibiting cell death in various cell types. Mcl-1 is highly expressed in HNSCC (17).

\section{Materials and methods}

Cells and reagents. The HNSCC SCC9, SCC25 and FADU cell lines were obtained from the American Type Culture Collection (Manassas, VA, USA). CAL27 was obtained from the German Collection of Microorganisms and Cell Cultures (DSMZ, Braunschweig, Germany). Tumor cells were cultured in RPMI 
medium (Cambrex, Walkersville, MD, USA) supplemented with $10 \%$ fetal bovine serum (PAA Laboratories, Linz, Austria) and $1 \%$ penicillin-streptomycin (Gibco BRL, Gaithersburg, MD, USA) at $37^{\circ} \mathrm{C}$ in a humidified atmosphere of $5 \% \mathrm{CO}_{2}$. ATO was purchased from Sigma-Aldrich (St. Louis, MO, USA). Cisplatin was obtained from a ready-to-use infusion.

Cytotoxicity assay. A CCK-8 cell proliferation assay (Dojindo Molecular Technologies, Gaithersburg, MD, USA) was used to determine the cytotoxic effects of ATO on tumor cells in vitro. Cells (3x10 $3 /$ well) were seeded into 96-well plates and incubated for $24 \mathrm{~h}$. The cells were then treated with increasing concentrations of ATO and cisplatin either alone or in combination (range, $0.25-16 \mu \mathrm{M}$ ). Untreated cells served as a control. Following $72 \mathrm{~h}$ of incubation, cell proliferation was measured by CCK-8 according to the manufacturer's protocol. Experiments were carried out in triplicate at least three times independently.

Analysis of combination effects. To determine the concentrations of the drugs to be investigated in the combination study, dose response curves were generated with Prism ${ }^{\circledR} 5.0$ software (GraphPad Software Inc., San Diego, CA, USA) for ATO and cisplatin alone. Experiments with ATO and cisplatin in a fixed ratio combination were carried out. Possible drug interactions were calculated with CalcuSyn software (Version 2.0, Biosoft, UK).

Immunocytochemistry. To visualize apoptosis we used the monoclonal mouse antibody M30 directed against a neo-epitope of cytokeratin 18 that is formed by caspase cleavage. Cells $\left(1 \times 10^{6}\right)$ were grown on glass slides and then treated with ATO for $48 \mathrm{~h}$. Untreated cells served as the control. Slides were fixed with ice-cold methanol $\left(-20^{\circ} \mathrm{C}\right)$ for $30 \mathrm{~min}$, washed twice in PBS and blocked with $1 \% \mathrm{BSA} / \mathrm{TBS}$ for $30 \mathrm{~min}$. Slides were then incubated overnight with M30 CytoDeath antibody (1:200, Roche, Vienna, Austria). As a control, slides were exposed to an $\mathrm{IgG}_{1}$ (Ancell, Bayport, MN, USA) antibody. After washing with TBS, slides were incubated with a multilink antibody (Dako, Glostrup, Denmark) for $1 \mathrm{~h}$ at room temperature (RT), washed, and again exposed to alkaline phosphatase-conjugated Streptavidin-AP/10\% human serum (Dako) for $1 \mathrm{~h}$ at RT. Visualization was performed with Fast Red TR, 4-chloro2-methylbenzenediazonium-salt (Sigma-Aldrich, St. Louis, MO, USA). Slides were then counterstained with hemalaun, dehydrated and mounted.

Western blot analysis. Cell monolayers were washed twice with cold PBS, frozen with liquid nitrogen and lysed with lysis buffer comprising 1\% NP40, 0.1\% SDS, $150 \mathrm{mM} \mathrm{NaCl}, 50 \mathrm{mM}$ TRIS, pH 7.4, 10 mM EDTA, 10 mM p-nitrophenolphosphate, $250 \mathrm{U} / 1$ aprotinin, $40 \mu \mathrm{g} / \mathrm{ml}$ leupeptin, $1 \mathrm{mM}$ PMSF, $1 \mathrm{mM}$ sodium orthovanadate, $10 \mathrm{mM}$ sodium fluoride and $40 \mathrm{mM}$ $\beta$-glycerolphosphate. The lysates were centrifuged at $14,000 \mathrm{rpm}$ at $4^{\circ} \mathrm{C}$ for $20 \mathrm{~min}$ and the supernatants were collected. Protein concentrations were determined using a Micro BCA protein counting kit from Pierce (Rockford, IL, USA). Protein $(20 \mu \mathrm{g})$ was separated by SDS-PAGE (10\%) and electroblotted onto nitrocellulose membranes (Schleicher \& Schuell, Dassel, Germany). Subsequent to blocking with 5\% BSA in TBS-Tween overnight, membranes were incubated with the appropriate diluted primary antibody. Bound antigen was visualized using the ECL Western blotting detection system (Amersham Life Sciences, Buckinghamshire, UK) and deteced using the ChemiDoc-It Imaging System (UVP, Upland, CA, USA).

Flow cytometry. The SCC9, SCC25, CAL27 and FADU cell lines were seeded in 6-well plates at a density of 100,000 cells/ well. After $24 \mathrm{~h}$, cells were treated with $10 \mu \mathrm{M}$ cisplatin (as a positive control), medium (as a negative control), $2 \mu \mathrm{M}$ ATO or $2 \mu \mathrm{M}$ cisplatin, or a combination of $2 \mu \mathrm{M}$ ATO and $2 \mu \mathrm{M}$ cisplatin. Apoptosis was measured after 48 and $72 \mathrm{~h}$ using the Annexin-V Apoptosis detection kit (Bender MedSystems, Vienna, Austria). Apoptosis was defined as $\mathrm{Ann}^{+} / \mathrm{PI}^{-}$. Ann $/ \mathrm{PI}^{+}$ and $\mathrm{Ann}^{+} / \mathrm{PI}^{+}$were defined as necrotic. Late apoptosis and necrosis cannot be differentiated with this assay.

Statistical analysis. Statistical analysis was performed using Prism $^{\circledR} 5.0$ software (GraphPad Software Inc., San Diego, CA, USA).

\section{Results}

Effects of ATO or cisplatin as single agents on cell growth. The HNCC SCC9, SCC25, CAL27 and FADU cell lines were exposed to ATO or cisplatin at doses of between $0.25 \mu \mathrm{M}$ and $16 \mu \mathrm{M}$ for $72 \mathrm{~h}$. Growth inhibition was measured with the CCK-8 assay. ATO and cisplatin administration induced a dose-dependent inhibition of cell proliferation (Fig. 1). $\mathrm{IC}_{50}$ ranged from $1.66 \mu \mathrm{M}(\mathrm{SEM} \pm 1.06 \%)$ to $3.20 \mu \mathrm{M}(\mathrm{SEM} \pm$ $1.10 \%)$ for ATO and from $2.32 \mu \mathrm{M}(\mathrm{SEM} \pm 1.11 \%)$ to $4.79 \mu \mathrm{M}$ $(\mathrm{SEM} \pm 1.07 \%)$ for cisplatin (Table I).

Effects of combined treatment with ATO and cisplatin on cell growth. For the combination studies, cells were treated simultaneously with $0.25-16 \mu \mathrm{M}$ ATO and $0.25-16 \mu \mathrm{M}$ cisplatin at a fixed ratio. The combined regimen showed higher cytotoxic effects in all four cell lines than each drug alone (Fig. 1). Combined drug effect was quantified by combination index (CI) analysis with the CalcuSyn software (Version 2.0, Biosoft) and expressed as $\mathrm{CI}$ versus $\mathrm{Fa}$ (fraction affected). $\mathrm{CI}<1$ indicated synergy; $\mathrm{CI}=1$ an additive effect; and $\mathrm{CI}>1$ indicated antagonism. Our experiments showed that ATO in combination with cisplatin acts synergistically at high doses in all four tested cell lines (Fig. 2). An additive effect was observed in CAL27 and FADU over a wide dose range.

Visualization of apoptosis by immunocytochemistry. To visualize apoptotic cells we used the M30 antibody, which detects caspase-cleaved cytokeratin-18 fragments. ATO-treated cells showed a higher rate of apoptosis in the SCC9, SCC25 and CAL27 cell lines than in the untreated control (Fig. 3). The cancer cell line FADU did not adhere to the glass slides.

Regulation of the anti-apoptotic protein Mcl-1. Western blot analysis of Mcl-1 (Santa Cruz Biotechnology, Santa Cruz, CA, USA) was performed to determine the regulation of apoptosisrelated proteins following treatment. Cells were collected prior to and following 12,24 and $48 \mathrm{~h}$ of treatment with $2 \mu \mathrm{M}$ ATO or $2 \mu \mathrm{M}$ cisplatin alone, or $2 \mu \mathrm{M}$ ATO and $2 \mu \mathrm{M}$ cisplatin in combination. Tubulin (Neomarkers, CA, USA) antibody served 
Scc9

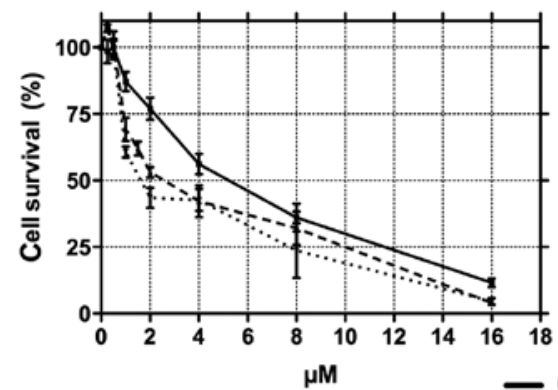

$\mu \mathrm{M}$

CAL27

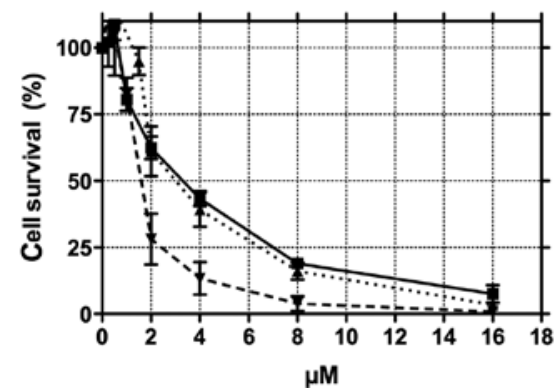

SCC25

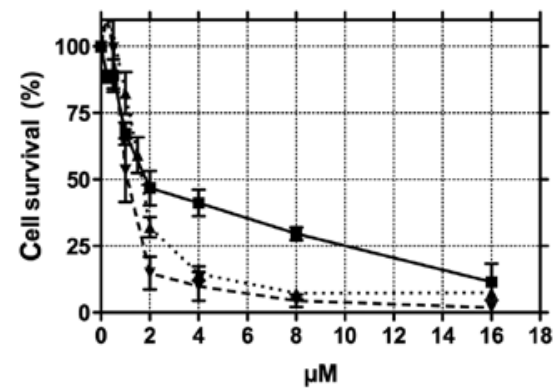

FADU

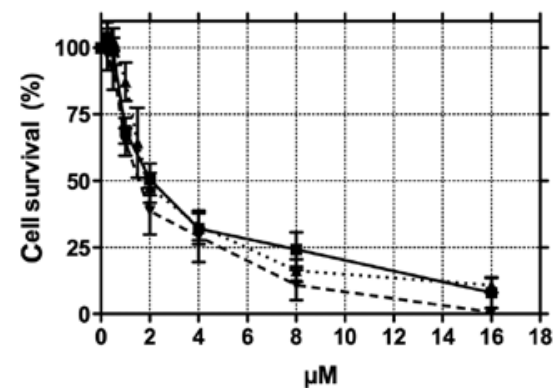

Figure 1. Dose-response curves. Arsenic trioxide, cisplatin and the combination after $72 \mathrm{~h}$ of exposure in the HNSCC SCC9, SCC25, CAL27 and FADU cell lines.

Table I. Effects of cisplatin and ATO on cell growth.

\begin{tabular}{lccc}
\hline & Cisplatin & ATO & ATO+Cisplatin \\
\hline SCC9 & & & \\
$\quad \mathrm{IC}_{50}$ & 4.79 & 2.83 & 2.26 \\
$\quad$ SEM of $\mathrm{IC}_{50}$ & 1.07 & 1.10 & 1.45 \\
$\mathrm{SCC} 25$ & & & \\
$\quad \mathrm{IC}_{50}$ & 2.41 & 1.66 & 1.09 \\
$\quad \mathrm{SEM}$ of $\mathrm{IC}_{50}$ & 1.12 & 1.06 & 1.09 \\
$\mathrm{CAL} 27$ & & & \\
$\mathrm{IC}_{50}$ & 3.11 & 3.2 & 1.54 \\
$\quad \mathrm{SEM}$ of $\mathrm{IC}_{50}$ & 1.07 & 1.10 & 1.09 \\
$\mathrm{FADU}$ & & & \\
$\mathrm{IC}_{50}$ & 2.32 & 2.38 & 1.69 \\
SEM of $\mathrm{IC}_{50}$ & 1.11 & 1.10 & 1.11 \\
\hline
\end{tabular}

SEM, standard error of the mean.

as a control. The analysis showed no significant alteration in the expression of the anti-apoptotic protein Mcl-1 following treatment with ATO alone or with the combination (data not shown).

Rate of apoptosis after treatment with ATO and cisplatin alone or in combination. ATO induced apoptosis in the four cancer cell lines alone and in combination with cisplatin. Apoptotic rates following $72 \mathrm{~h}$ of treatment were found to be higher than after $48 \mathrm{~h}$. The highest apoptotic rates following treatment with $2 \mu \mathrm{M}$ ATO were observed in the $\mathrm{SCC} 25$ and FADU cell lines, whereas apoptosis in the SCC9 cell line

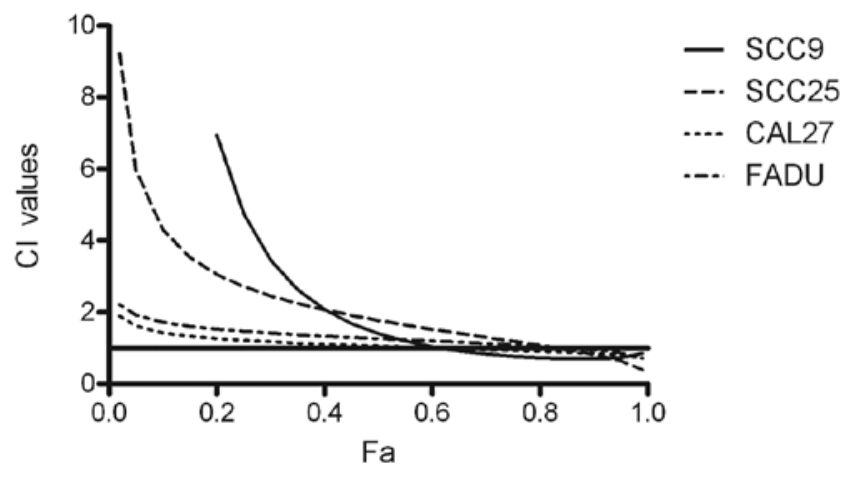

Figure 2. $\mathrm{CI}$ values. $\mathrm{CI}<1$ indicates synergy, $\mathrm{CI}=1$ indicates an additive effect and $\mathrm{CI}>1$ indicates antagonism. CI, combination index.

was minimal. Notably, the combination of ATO and cisplatin showed no higher apoptosis rates than each drug alone (Fig. 4).

\section{Discussion}

Head and neck squamous cell carcinoma is an aggressive and often lethal malignancy. Treatment remains poor and new therapeutic strategies are required to identify new drugs that induce apoptosis in malignant tumors.

For many centuries, arsenic preparations have been used through empirical observation for the treatment of numerous diseases (18). ATO has been successfully used in the treatment of APL and has been shown to be effective even in patients resistant to conventional chemotherapy (19). Studies have shown that ATO induces apoptosis and loss of the PML/AR $\alpha$ fusion oncoprotein, a protein that is specific for APL, leading 

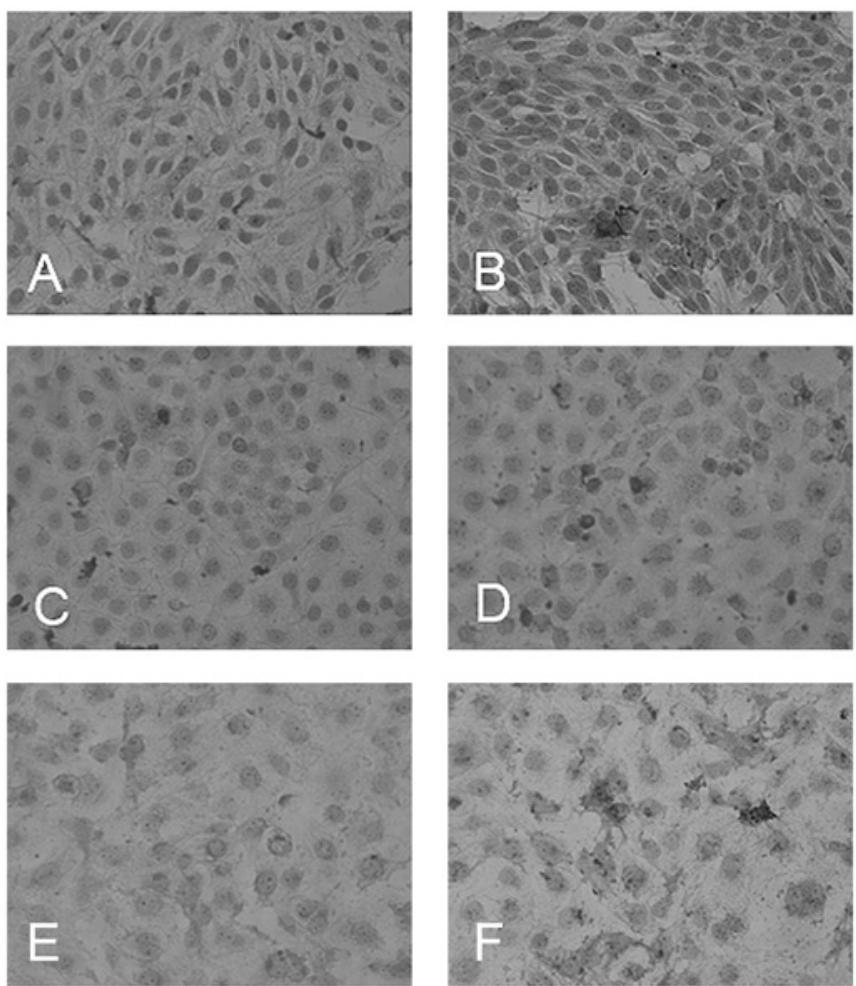

Figure 3. Immunohistochemistry. To visualize apoptosis, ATO-treated cells were incubated with the M30 antibody. Slides were stained with Fast Red and counterstained with hemalaun. The photomicrographs were captured at a magnification of x200. Untreated control: (A) SCC9, (C) SCC25 and (E) CAL27. Treated with $2 \mu \mathrm{M}$ ATO: (B) SCC9, (D) SCC25 and (F) CAL27.

to differentiation of leukaemic cells $(20,21)$. Since successful results have been achieved, arsenic trioxide is regarded as a potential anticancer agent, not only for hematological malignancies but also for malignant diseases such as HNSCC.
Cisplatin is a standard agent of head and neck cancer chemotherapy. Although concurrent chemoradiotherapy is well established as an effective treatment for squamous cell carcinoma, it is to the impairment of advanced toxicity in normal tissue. Therefore, this study was conducted to identify a new combination regimen with cisplatin.

In the present study, we investigated the effects of ATO alone and in combination with cisplatin on the HNSCC cell lines SCC9, SCC25, CAL27 and FADU. Our results showed that ATO is an effective cytotoxic drug in vitro for head and neck cancer. Treatment of the four cell lines led to an inhibited proliferation in a dose-dependent manner with the $\mathrm{IC}_{50}$ ranging from 1.66 to $3.20 \mu \mathrm{M}$. Our results are in accordance with those of Seol et al (22), who demonstrated a dose-dependent cytotoxicity of ATO and revealed that ATO is capable of inducing apoptosis in head and neck cancer cells.

Few studies have reported the combined effect of ATO and cisplatin. In their study, Wang et al (23) showed that in human hepatoma cells the inhibition rates of ATO in combination with cisplatin are higher than those of ATO or cisplatin alone. In this study, the interaction between ATO and cisplatin was reported as synergistic. Other studies in lung and ovarian cancer cells also demonstrated a synergistic effect of ATO and cisplatin in vitro $(24,25)$. No studies are currently available regarding the combined effect of ATO and cisplatin in HNSCC. One study has examined the effect of tetra-arsenic oxide and cisplatin in head and neck cell lines (26), however, tetra-arsenic oxide has not yet been approved.

In the present study, we found a synergistic effect in the combination of ATO and cisplatin in the four tested HNSCC cell lines at high concentrations. A limiting factor, however, is that this was a single-dose drug application in a cytotoxicity assay. Comparison with clinical low-dose, long-term application requires further investigation.
$48 \mathrm{~h}$
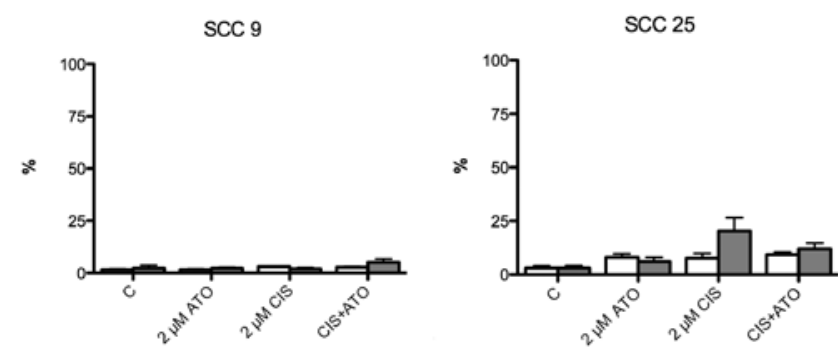

$72 \mathrm{~h}$
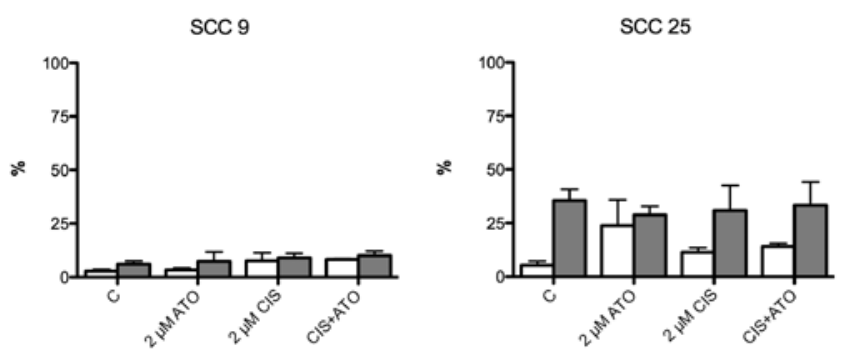
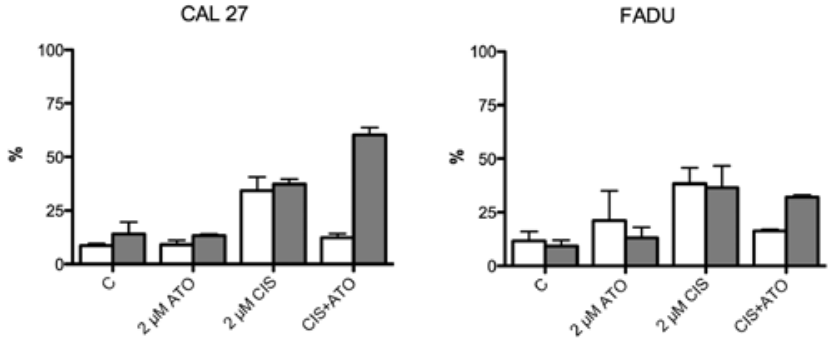

Figure 4. Flow cytometry. Cells were treated with $2 \mu \mathrm{M}$ ATO or $2 \mu \mathrm{M}$ cisplatin or in combination and analysed after 48 and $72 \mathrm{~h}$. 
We also investigated whether the two substances together would lead to increased rates of apoptosis. However, the flow cytometry did not reveal higher apoptotic rates for the combination compared to each drug alone.

Findings of the present study showed that the combination of ATO and cisplatin has an enhanced cytotoxic effect on the four HNSCC cell lines SCC9, SCC25, CAL27 and FADU after $72 \mathrm{~h}$ of treatment when compared to the use of a single drug. ATO and cisplatin had apoptotic properties in the four cell lines tested.

In conclusion, ATO appears to be a noteworthy substance in the treatment of head and neck cancer, due to its apoptotic properties and its limited side effects in clinical application. Adverse effects of established chemotherapeutics such as cisplatin may be reduced if used in combination with ATO, since lower doses of both agents may be possible.

\section{References}

1. Parkin DM, Bray F, Ferlay J and Pisani P: Global cancer statistics, 2002. CA Cancer J Clin 55: 74-108, 2005.

2. Miller WH Jr, Schipper HM, Lee JS, Singer J and Waxman S: Mechanisms of action of arsenic trioxide. Cancer Res 62: 3893-3903, 2002.

3. Gensini GF, Conti AA and Lippi D: The contributions of Paul Ehrlich to infectious disease. J Infect 54: 221-224, 2007.

4. Docampo R and Moreno SN: Current chemotherapy of human African trypanosomiasis. Parasitol Res 90 (Supp 1): S10-S13, 2003.

5. Soignet SL, Maslak P, Wang ZG, et al: Complete remission after treatment of acute promyelocytic leukemia with arsenic trioxide N Engl J Med 339: 1341-1348, 1998.

6. Shen ZX, Chen GQ, Ni JH, et al: Use of arsenic trioxide $\left(\mathrm{As}_{2} \mathrm{O}_{3}\right)$ in the treatment of acute promyelocytic leukemia (APL): II. Clinical efficacy and pharmacokinetics in relapsed patients. Blood 89: 3354-3360, 1997.

7. Soignet SL, Frankel SR, Douer D, et al: United States multicenter study of arsenic trioxide in relapsed acute promyelocytic leukemia. J Clin Oncol 19: 3852-3860, 2001.

8. Jiang XH, Wong BC, Yuen ST, et al: Arsenic trioxide induces apoptosis in human gastric cancer cells through up-regulation of p53 and activation of caspase-3. Int J Cancer 91: 173-179, 2001.

9. Seol JG, Park WH, Kim ES, et al: Effect of arsenic trioxide on cell cycle arrest in head and neck cancer cell line PCI-1. Biochem Biophys Res Commun 265: 400-404, 1999.

10. Akao Y, Nakagawa Y and Akiyama K: Arsenic trioxide induces apoptosis in neuroblastoma cell lines through the activation of caspase 3 in vitro. FEBS Lett 455: 59-62, 1999.
11. Shen ZY, Shen J, Li QS, Chen CY, Chen JY and Yi Z: Morphological and functional changes of mitochondria in apoptotic esophageal carcinoma cells induced by arsenic trioxide. World J Gastroenterol 8: 31-35, 2002.

12. Uslu R, Sanli UA, Sezgin C, et al: Arsenic trioxide-mediated cytotoxicity and apoptosis in prostate and ovarian carcinoma cell lines. Clin Cancer Res 6: 4957-4964, 2000.

13. Hussein MA, Saleh M, Ravandi F, Mason J, Rifkin RM and Ellison R: Phase 2 study of arsenic trioxide in patients with relapsed or refractory multiple myeloma. Br J Haematol 125: 470-476, 2004

14. Kim KB, Bedikian AY, Camacho LH, Papadopoulos NE and McCullough C: A phase II trial of arsenic trioxide in patients with metastatic melanoma. Cancer 104: 1687-1692, 2005.

15. Lin $\mathrm{CC}$, Hsu C, Hsu CH, Hsu WL, Cheng AL and Yang $\mathrm{CH}$ : Arsenic trioxide in patients with hepatocellular carcinoma: a phase II trial. Invest New Drugs 25: 77-84, 2007.

16. Schiller GJ, Slack J, Hainsworth JD, et al: Phase II multicenter study of arsenic trioxide in patients with myelodysplastic syndromes. J Clin Oncol 24: 2456-2464, 2006.

17. Whisler LC, Wood NB, Caldarelli DD, et al: Regulators of proliferation and apoptosis in carcinoma of the larynx. Laryngoscope 108: 630-638, 1998

18. Evens AM, Tallman MS and Gartenhaus RB: The potential of arsenic trioxide in the treatment of malignant disease: past, present, and future. Leuk Res 28: 891-900, 2004.

19. Soignet SL: Clinical experience of arsenic trioxide in relapsed acute promyelocytic leukemia. Oncologist 6 (Suppl 2): 11-16, 2001.

20. Chen GQ, Shi XG, Tang W, et al: Use of arsenic trioxide $\left(\mathrm{As}_{2} \mathrm{O}_{3}\right)$ in the treatment of acute promyelocytic leukemia (APL): I. $\mathrm{As}_{2} \mathrm{O}_{3}$ exerts dose-dependent dual effects on APL cells. Blood 89: 3345-3353, 1997.

21. Shao W, Fanelli M, Ferrara FF, et al: Arsenic trioxide as an inducer of apoptosis and loss of PML/RAR alpha protein in acute promyelocytic leukemia cells. J Natl Cancer Inst 90: 124-133, 1998.

22. Seol JG, Park WH, Kim ES, et al: Potential role of caspase-3 and -9 in arsenic trioxide-mediated apoptosis in PCI-1 head and neck cancer cells. Int J Oncol 18: 249-255, 2001.

23. Wang W, Qin SK, Chen BA and Chen HY: Experimental study on antitumor effect of arsenic trioxide in combination with cisplatin or doxorubicin on hepatocellular carcinoma. World J Gastroenterol 7: 702-705, 2001.

24. Li H, Zhu X, Zhang Y, Xiang J and Chen H: Arsenic trioxide exerts synergistic effects with cisplatin on non-small cell lung cancer cells via apoptosis induction. J Exp Clin Cancer Res 28: $110,2009$.

25. Zhang N, Wu ZM, McGowan E, et al: Arsenic trioxide and cisplatin synergism increase cytotoxicity in human ovarian cancer cells: therapeutic potential for ovarian cancer. Cancer Sci 100: 2459-2464, 2009.

26. Chung WH, Sung BH, Kim SS, Rhim H and Kuh HJ: Synergistic interaction between tetra-arsenic oxide and paclitaxel in human cancer cells in vitro. Int J Oncol 34: 1669-1679, 2009. 